\title{
Concentração e acúmulo de macronutrientes em alface cultivada em sistemas hidropônico e convencional ${ }^{1}$
}

\section{Concentration and accumulation of macronutrients in hydroponic and conventional lettuce}

\author{
Elisabete R. Yonamini Beninni²; Hideaki Wilson Takahashi²; \\ Carmen Silvia Vieira J. Neves ${ }^{2}$
}

Resumo

O estudo da absorção e do acúmulo de nutrientes é importante para determinação de épocas e de quantidades de adubação das culturas. $\mathrm{O}$ experimento teve como objetivo determinar a concentração e o acúmulo dos macronutrientes em alface cv. Verônica ao longo do seu desenvolvimento, cultivada em sistemas hidropônico e convencional. O delineamento estatístico foi em blocos, com seis repetições e parcelas subdivididas, tendo como parcela principal os sistemas hidropônico e convencional e como subparcela as épocas de coleta das amostras. A cada sete dias, colhiam-se plantas para análises químicas de N, P, K, Ca, Mg e S. Plantas cultivadas em sistema hidropônico apresentaram período de cultivo mais curto do que no sistema convencional. As concentrações de N, P, K, Ca, Mg e S no ponto de colheita para a parte aérea das plantas cultivadas em sistema hidropônico foram: 44,$80 ; 8,54 ; 87,42 ; 10,29 ; 3,31$; $2,32 \mathrm{~g} \mathrm{Kg}^{-1}$, e para as plantas cultivadas em sistema convencional foram: 38,24; 5,74; 78,33; 12,$23 ; 3,11 \mathrm{e}$ $3,87 \mathrm{~g} \mathrm{Kg}^{-1}$, respectivamente. $\mathrm{O}$ acúmulo de nutrientes pela parte aérea foi 581,$10 ; 110,60 ; 1.135,76$; 133,$81 ; 42,97$ e 30,08 mg por planta de N, P, K, Ca, Mg e S para as cultivadas em sistema hidropônico e 372,$78 ; 56,11 ; 765,84 ; 119,05 ; 30,46$ e $37,81 \mathrm{mg}$ por planta, respectivamente, para as cultivadas em sistema convencional.

Palavras-chave: Lactuca sativa L., nutrientes, absorção, hidroponia

\begin{abstract}
The study of absorption and accumulation of nutrients is important to determine the date and quantity of fertilizer for crops. The aim of this study was to evaluate the concentration and accumulation of macronutrients in hydroponic and conventional lettuce, cv. Verônica, during crop development. The statistical design was blocks with six replications in split plot. The main plots were hydroponic and conventional system and the subplots were the dates of harvest. Every seven days plants were harvested and analyzed for $\mathrm{N}, \mathrm{P}, \mathrm{K}, \mathrm{Ca}, \mathrm{Mg}$ and $\mathrm{S}$. The hydroponic plants had the cycle shorter than conventional plants. Concentration of $\mathrm{N}, \mathrm{P}, \mathrm{K}, \mathrm{Ca}, \mathrm{Mg}$ and $\mathrm{S}$ at the harvest in the plant above ground parts in hydroponic system were $44.80 ; 8.54 ; 87.42 ; 10.29 ; 3.31 ; 2.32 \mathrm{~g} \mathrm{Kg}^{-1}$ and in conventional system were $38 ., 24 ; 5.74 ; 78.33 ; 12.23 ; 3.11$ and $3.87 \mathrm{~g} \mathrm{Kg}^{-1}$, respectively. The accumulation were 581.10; 110.60; $1,135.76 ; 133.81 ; 42.97$ and $30.08 \mathrm{mg}$ of N, P, K, Ca, Mg and $\mathrm{S}$ by plant in hydroponic system and 372.78; $56.11 ; 765.84 ; 119.05 ; 30.46$ and $37.81 \mathrm{mg}$, respectively, in conventional system.
\end{abstract}

Key words: Lactuca sativa L., nutrients, uptake, hydroponics

\footnotetext{
${ }^{1}$ Parte da dissertação do mestrado do primeiro autor, apresentada à Universidade Estadual de Londrina.

${ }^{2}$ UEL, Departamento de Agronomia, C. Postal 6001, CEP 86.051-990. Londrina - PR. E-mail: hwilson@uel.br.

* Autor para correspondência.
} 


\section{Introdução}

A alface (Lactuca sativa L.) é uma das hortaliças folhosas mais cultivadas no mundo (MEDINA et al., 1982) e a mais importante na alimentação do brasileiro, o que lhe assegura expressiva importância econômica (FAQUIN; FURTINI NETO; VILELA, 1996). Assim como várias outras hortaliças, exige um fornecimento considerável de nutrientes prontamente solúveis dentro de um curto período de intenso crescimento vegetativo (GARCIA, 1982), sendo portanto comum a aplicação, pelos produtores, de doses maciças de fertilizantes para atender à demanda de nutrientes da cultura. Para obter altos rendimentos e otimizar o fornecimento de nutrientes, é importante conhecer a necessidade da cultura nas diferentes fases de crescimento, para fornecê-los adequadamente (PAPADOPOULOS; KHOSLA, 1995). De acordo com Sutcliffe e Baker (1983) as concentrações dos elementos nas plantas variam amplamente entre as espécies e variedades, dependendo do genótipo e condições ambientais em que estão se desenvolvendo.

No Brasil, tem crescido nos últimos anos o interesse pelo cultivo hidropônico, predominando o sistema NFT - nutrient film technique, ou fluxo laminar de nutrientes (FURLANI et al., 1999), em que as raízes ficam submersas em uma fina lâmina de solução nutritiva. A alface é a hortaliça mais cultivada neste sistema, representando $80 \%$ da produção hidropônica total (FURLANI, 1999), devido a facilidade de cultivo, grande demanda pelo mercado e redução do período de cultivo (GUALBERTO; RESENDE; BRAZ,1999). Com o uso da hidroponia consegue-se um controle mais eficiente dos nutrientes, facilitando o monitoramento da composição da solução nutritiva (HEINEN; JAGER; NIERS, 1991).

De acordo com Faquin e Furlani (1999), estudos sobre a nutrição mineral de hortaliças cultivadas em hidroponia, com a determinação das exigências nutricionais de cada espécie, são essenciais para o estabelecimento das concentrações e proporções dos nutrientes, tanto para a formulação da solução nutritiva básica, quanto para a reposição periódica dos nutrientes ao longo dos estádios fenológicos da cultura.

Poucos estudos foram realizados visando determinar a absorção de nutrientes pela alface durante o seu ciclo de desenvolvimento. Garcia (1982) e Fernandes, Oliveira e Haag (1981) avaliaram o comportamento da alface quando cultivada a campo e Koefender (1996) em sistema hidropônico. Desta forma, o objetivo do experimento foi determinar a concentração e o acúmulo dos macronutrientes durante o ciclo da alface, cv. Verônica, cultivada em sistemas hidropônico e convencional.

\section{Material e Métodos}

Foram utilizadas sementes de alface tipo crespa, cv. Verônica. A semeadura foi realizada em bandejas de poliestireno expandido, tendo uma mistura de vermiculita com húmus como substrato. A irrigação foi feita diariamente e, após 20 dias, as mudas foram retiradas das bandejas e transferidas para o cultivo a campo e hidropônico. O experimento a campo localizou-se em Faxinal - Pr e o experimento no sistema hidropônico foi realizado na área experimental do Departamento de Agronomia da Universidade Estadual de Londrina, em ambiente protegido. As mudas transferidas para o sistema hidropônico tiveram suas raízes lavadas para retirada do substrato. O transplante realizou-se em 28.04.01 para os dois sistemas e a colheita das alfaces cultivadas em sistema hidropônico foi dia 08.06 .01 e a campo em 15.06.01.

No sistema hidropônico, a solução nutritiva utilizada foi baseada em Hoagland e Arnon (1950). O reservatório com solução nutritiva foi completado diariamente com água e o $\mathrm{pH}$ corrigido entre 5,6 e 6,2 adicionando-se $\mathrm{HNO}_{3} 0,1 \mathrm{~N}$ ou KOH $0,1 \mathrm{~N}$ para reduzir ou elevar o $\mathrm{pH}$, respectivamente. $\mathrm{O}$ sistema possuía 4 canaletas de PVC com $10 \mathrm{~m}$ de comprimento e $2 \%$ de declividade. $\mathrm{O}$ espaçamento entre plantas até os primeiros 21 dias foi de $0,10 \mathrm{x}$ $0,20 \mathrm{~m}$ e após essa data, foi de $0,20 \times 0,20 \mathrm{~m}$. 
A circulação da solução nutritiva foi realizada por uma bomba com potência de 0,5 HP e controlada por um temporizador que a mantinha 20 minutos ligada e 10 minutos desligada das 8:00 às 19:00 h e 10 minutos ligada e 20 minutos desligada das 19:00 às 8:00 h. A temperatura dentro da estufa variou entre $6^{\circ}$ e $34^{\circ} \mathrm{C}$

A primeira troca da solução nutritiva ocorreu quando a condutividade elétrica (CE) foi $1,67 \mathrm{dS} \mathrm{cm}^{-}$ ${ }^{1}$ ( $\left.11^{\circ} \mathrm{dia}\right)$. Do $11^{\circ}$ ao $21^{\circ}$ dia as trocas foram semanais e após o $21^{\circ}$ dia, a cada 4 dias. A condutividade elétrica foi monitorada diariamente e, quando estava abaixo de 1,8 $\mathrm{dS} \mathrm{cm}^{-1}$, adicionava-se uma solução concentrada de macronutrientes para elevar a $\mathrm{CE}$ para 2,0 dS cm$~^{-1}$. A quantidade de solução nutritiva por planta até o $11^{\circ}$ dia após transplante foi $0,71 \mathrm{~L}$ e após, $1 \mathrm{~L}$.

Foram coletadas semanalmente $48,15,8,4,3,2$ e 2 plantas respectivamente para as $1^{\mathrm{a}}, 2^{\mathrm{a}}, 3^{\mathrm{a}}, 4^{\mathrm{a}}, 5^{\mathrm{a}}$, $6^{\mathrm{a}}$ e $7^{\mathrm{a}}$ semanas após o transplante, para realização das análises químicas. Todas as plantas foram separadas em parte aérea e raiz. A parte aérea foi lavada em água corrente e a raiz em águas corrrente e destilada, solução diluída de detergente, água destilada, solução $\mathrm{HCl} 0,1 \mathrm{~N}$ e finalmente água deionizada. Após as colheitas das plantas, tampavamse os orifícios das canaletas com isopor para evitar evaporação e desenvolvimento de algas.

O experimento realizado à campo foi conduzido em canteiro com espaçamento de $0,20 \times 0,20 \mathrm{~m}$. A análise química do solo apresentou as seguintes características: Matéria Orgânica $=37,16 \mathrm{~g} \mathrm{dm}^{-3} ; \mathrm{pH}$ em $\mathrm{CaCl}_{2}=5,5 ; \mathrm{H}=3,97$ cmolc $_{3} \mathrm{dm}^{-3} ; \mathrm{Al}=0$ cmolc $_{3}$ $\mathrm{dm}^{-3} ; \mathrm{H}+\mathrm{Al}=6,3 \mathrm{cmolc}_{3} \mathrm{dm}^{-3} ; \mathrm{Ca}=6,64 \mathrm{cmolc}_{3} \mathrm{dm}^{-}$ 3; $\mathrm{Mg}=3,45 \mathrm{cmolc}_{3} \mathrm{dm}^{-3} ; \mathrm{K}=0,72 \mathrm{cmolc}_{3} \mathrm{dm}^{-3} ; \mathrm{P}=$ $44,72 \mathrm{mg} \mathrm{dm}^{-3} ; \mathrm{Mn}=111,4 \mathrm{mg} \mathrm{dm}^{-3} ; \mathrm{Fe}=157,00 \mathrm{mg}$ $\mathrm{dm}^{-3} ; \mathrm{Cu}=0,78 \mathrm{mg} \mathrm{dm}^{-3}, \mathrm{Zn}=24,8 \mathrm{mg} \mathrm{dm}^{-3} \mathrm{e} \mathrm{B}=$ $0,74 \mathrm{mg} \mathrm{dm}^{-3}$. Não foi necessária aplicação de defensivos agrícolas, o controle do mato foi realizado com enxada e a irrigação por aspersão. A temperatura durante o experimento variou entre $5^{\circ}$ e $30^{\circ} \mathrm{C}$, com precipitação de $199 \mathrm{~mm}$.
Da mesma forma que para o cultivo hidropônico, semanalmente foram coletadas e lavadas em água corrente plantas cultivadas no sistema convencional para as análises químicas.

Todas as amostras (sistemas hidropônico e convencional) foram secas em estufa com circulação de ar a $65^{\circ} \mathrm{C}$ e moídas para realização das análises químicas de N, P, K, Ca, Mg e S. Para a determinação do nitrogênio, foi feita a digestão sulfúrica e destilação pelo micro Kjeldahl. Para os demais nutrientes realizou-se digestão nítricoperclórica e a partir do extrato determinou-se cálcio e magnésio por absorção atômica, enxofre por turbidimetria de sulfato de bário, fósforo pelo método colorimétrico e potássio por fotometria de chama.

Os experimentos foram realizados em blocos com 6 repetições, arranjadas em parcelas subdivididas, tendo como parcela principal os sistemas hidropônico e convencional e como subparcela as datas de coleta das amostras. Inicialmente cada parcela possuía 56 plantas. Para comparação de médias dos nutrientes e massas entre os sistemas hidropônico e convencional utilizou-se Tukey a 5\% e para o estudo da associação entre massa seca e acúmulo de nutrientes utilizou-se Correlação de Pearson.

\section{Resultados e Discussão}

O período de cultivo da alface no sistema hidropônico foi de 42 dias e no sistema convencional foi de 49, representando o ponto de colheita em ambos os sistemas. Esse maior período de cultivo das plantas cultivadas no sistema convencional pode ser atribuído ao desenvolvimento de novas raízes em substituição àquelas existentes no transplante, que são degradadas após serem transferidas para o campo, fato que não ocorre no cultivo hidropônico. Além disso, na hidroponia todos os nutrientes encontravam-se em quantidades e proporções adequadas durante todo o período de cultivo.

$\mathrm{O}$ acúmulo de matéria fresca total quando as plantas foram cultivadas no sistema hidropônico foi 
lento até 21 dias após transplante, representando $17,97 \%$ do total acumulado (Tabela 1). As raízes apresentaram um acúmulo mais homogêneo durante o ciclo da cultura e nesse mesmo período haviam acumulado $34,53 \%$ do seu peso final, enquanto que a parte aérea acumulara $14,92 \%$. Nos 14 dias finais de cultivo houve um grande incremento no desenvolvimento das plantas, representando um acúmulo de 55,44\% do total da parte aérea e 51,80\% de toda matéria fresca acumulada. Neste sistema, o acúmulo de matéria fresca da parte aérea foi superior ao do sistema convencional, a partir da terceira semana de cultivo. Na colheita, as plantas possuíam em média $330,88 \mathrm{~g}$ por planta de peso fresco total, sendo $84,45 \%$ representado pela parte aérea (Tabela 1) e equivalente a uma produtividade acima de 37.000 $\mathrm{Kg} \mathrm{ha}^{-1}$ (Tabela 5). Estudando a reposição da solução nutritiva em sistema hidropônico, Koefender (1996) obteve produção total de material fresco de alface, cv. Verônica, inferior ao obtido neste experimento, variando entre 207,80 e 230,44 g por planta.

Tabela 1 - Acúmulo de matéria fresca e seca (g por planta) durante o desenvolvimento da alface, cv. Verônica, cultivada em sistemas hidropônico e convencional. UEL, Londrina, 2001.

\begin{tabular}{|c|c|c|c|c|c|c|c|c|c|c|}
\hline \multirow{3}{*}{$\begin{array}{l}\text { Dias } \\
\text { após } \\
\text { transp. }\end{array}$} & \multirow{2}{*}{\multicolumn{3}{|c|}{$\frac{\text { CONVENCIONAL }}{\text { P. aérea }}$}} & \multicolumn{7}{|c|}{ HIDROPÔNICO } \\
\hline & & & & \multicolumn{3}{|c|}{ P. aérea } & \multicolumn{2}{|c|}{ Raiz } & \multicolumn{2}{|c|}{ Total } \\
\hline & $\mathrm{g}$ & & $\%$ & $\mathrm{~g}$ & & $\%$ & g & $\%$ & $\mathrm{~g}$ & $\%$ \\
\hline \multicolumn{11}{|c|}{ Matéria fresca } \\
\hline 0 & 3,04 & $\mathrm{a}$ & $1,13^{(1)}$ & 3,04 & $\mathrm{a}$ & 1,09 & 0,55 & 1,07 & 3,59 & 1,09 \\
\hline 7 & 2,52 & $\mathrm{a}$ & 0,94 & 8,81 & $\mathrm{a}$ & 3,15 & 4,20 & 8,16 & 13,01 & 3,93 \\
\hline 14 & 5,77 & $\mathrm{a}$ & 2,14 & 25,13 & $\mathrm{a}$ & 8,99 & 11,90 & 23,14 & 37,04 & 11,19 \\
\hline 21 & 11,69 & $\mathrm{~b}$ & 4,35 & 41,69 & $\mathrm{a}$ & 14,92 & 17,77 & 34,53 & 59,45 & 17,97 \\
\hline 28 & 55,30 & $\mathrm{~b}$ & 20,56 & 124,51 & $\mathrm{a}$ & 44,56 & 34,98 & 67,98 & 159,49 & 48,20 \\
\hline 35 & 105,15 & $\mathrm{~b}$ & 39,10 & 204,08 & $\mathrm{a}$ & 73,04 & 41,81 & 81,25 & 245,89 & 74,31 \\
\hline 42 & 160,94 & $\mathrm{~b}$ & 59,85 & 279,42 & $\mathrm{a}$ & 100,00 & 51,46 & 100,00 & 330,88 & 100,00 \\
\hline 49 & 268,92 & & 100,00 & - & & - & - & - & - & - \\
\hline \multicolumn{11}{|c|}{$\mathrm{CV}_{1}^{(2)}=20,86 \% \mathrm{CV}_{2}=17,17 \%$} \\
\hline \multicolumn{11}{|c|}{ Matéria seca } \\
\hline 0 & 0,13 & $\mathrm{a}$ & 1,31 & 0,13 & $\mathrm{a}$ & 0,99 & 0,02 & 0,86 & 0,15 & 0,97 \\
\hline 7 & 0,21 & a & 2,18 & 0,59 & $\mathrm{a}$ & 4,55 & 0,14 & 5,99 & 0,73 & 4,77 \\
\hline 14 & 0,40 & $\mathrm{~b}$ & 4,09 & 1,51 & $\mathrm{a}$ & 11,63 & 0,42 & 17,65 & 1,92 & 12,56 \\
\hline 21 & 0,85 & $\mathrm{~b}$ & 8,70 & 2,58 & $\mathrm{a}$ & 19,89 & 0,74 & 31,38 & 3,32 & 21,65 \\
\hline 28 & 1,88 & $\mathrm{~b}$ & 19,20 & 6,42 & $\mathrm{a}$ & 49,56 & 1,47 & 62,41 & 7,89 & 51,54 \\
\hline 35 & 4,06 & $\mathrm{~b}$ & 41,51 & 9,50 & $\mathrm{a}$ & 73,33 & 1,81 & 76,88 & 11,31 & 73,88 \\
\hline 42 & 6,81 & $\mathrm{~b}$ & 69,56 & 12,96 & $\mathrm{a}$ & 100,00 & 2,35 & 100,00 & 15,31 & 100,00 \\
\hline 49 & 9,78 & & 100,00 & - & & - & - & - & - & - \\
\hline \multicolumn{11}{|c|}{$\mathrm{CV}_{1}=23,48 \% \mathrm{CV}_{2}=14,66 \%$} \\
\hline
\end{tabular}

(1) Médias seguidas de mesma letra na linha, não diferem entre si, pelo Teste de Tukey a 5\%.

(2) $\mathrm{CV}_{1}=$ Coeficiente de variação da parcela; $\mathrm{CV}_{2}=$ Coeficiente de variação da subparcela. 
O comportamento do acúmulo de matéria seca das plantas cultivadas em sistema hidropônico foi semelhante ao de matéria fresca. Na colheita, a produção de material seco total foi de 15,31 g por planta, sendo $12,96 \mathrm{~g}$ de parte aérea e $2,35 \mathrm{~g}$ de raízes (Tabela 1). Em diferentes condutividades elétricas da solução nutritiva, Costa et al. (2001) obtiveram produção de matéria seca da parte aérea por planta variando entre 8,12 e $24,50 \mathrm{~g}$ e a raiz entre $3,22 \mathrm{e}$ 3,38 g, já Koefender (1996) trabalhando com a cv. Verônica obteve por planta entre 8,40 e 9,93 g para a planta inteira e 0,90 e 1,05 g para as raízes, valores inferiores aos deste experimento. Na Tabela 2 podese observar a produção de material seco em $\mathrm{Kg}^{-} \mathrm{ha}^{-}$ 1: 2.041,92, 1.727,87 e 314,04 para produção total, parte aérea e raízes, respectivamente.

Tabela 2 - Acúmulo de matéria fresca, matéria seca e nutrientes $\left(\mathrm{Kg} \mathrm{ha}^{-1}\right)$ em alface, cv. Verônica, cultivada em sistemas hidropônico e convencional, no ponto de colheita. Londrina, UEL, 2001.

\begin{tabular}{|c|c|c|c|c|c|c|c|c|}
\hline & $\begin{array}{l}\text { Matéria } \\
\text { fresca }\end{array}$ & $\begin{array}{l}\text { Matéria } \\
\text { seca }\end{array}$ & $\mathrm{N}$ & $\mathrm{P}$ & $\mathrm{K}$ & $\mathrm{Ca}$ & $\mathrm{Mg}$ & S \\
\hline \multicolumn{9}{|c|}{ Hidropônico } \\
\hline$P$. aérea & $37.256,57$ & $1.727,87$ & 77,48 & 14,75 & 151,43 & 17,84 & 5,73 & 4,01 \\
\hline Raiz & $6.861,09$ & 314,04 & 12,15 & 3,25 & 13,13 & 0,93 & 0,33 & 1,42 \\
\hline Total & $44.117,67$ & $2.041,92$ & 89,63 & 17,99 & 164,56 & 18,77 & 6,05 & 5,43 \\
\hline \multicolumn{9}{|c|}{ Convencional } \\
\hline P. aérea & $35.855,47$ & $1.304,45$ & 49,70 & 7,48 & 102,11 & 15,87 & 4,06 & 5,04 \\
\hline
\end{tabular}

No sistema convencional as plantas apresentaram incremento de matéria fresca e seca da parte aérea mais lentamente do que no sistema hidropônico. Porém, na última semana de cultivo, houve um aumento de $40,15 \%$ do acúmulo de matéria fresca e $30,44 \%$ de matéria seca (Tabela 1). Na colheita, a planta possuía em média 268,92 g de matéria fresca e 9,78 g de matéria seca (Tabela 01), equivalentes a $35.855,47$ e $1.304,45 \mathrm{Kg} \mathrm{ha}^{-1}$, respectivamente (Tabela 2). A produtividade máxima estimada por Rodrigues e Casali (1999) foi de 153,9 g por planta quando trabalharam com diferentes doses de adubações orgânica e mineral em alface cv. Babá. Garcia (1982), estudando o comportamento de duas cultivares de alface, obteve produção de matéria seca por planta de 12,75 g para cv. Brasil 48 e 12,52 g para cv. Clause's Aurélia.

A concentração média de nitrogênio da parte aérea das plantas cultivadas em sistema hidropônico aumentou até os 14 dias após transplante, tornandose constante a partir desta data. Nas cultivadas em sistema convencional, essa concentração foi constante dos 14 aos 35 dias após transplante, para depois apresentar queda significativa (Tabela 3). $\mathrm{O}$ valor obtido no sistema hidropônico foi estatisticamente superior ao encontrado no sistema convencional quando comparados aos 42 dias após transplante. A concentração de fósforo nas plantas cultivadas em sistema hidropônico apresentou variações até os 21 dias após transplante, tornandose constante após essa data; já nas cultivadas em sistema convencional, essa concentração permaneceu constante do $7^{\circ}$ dia após transplante até a colheita. Em todas as coletas, as concentrações de fósforo das plantas do sistema hidropônico foram significativamente superiores às do sistema convencional (Tabela 3). Com relação às concentrações de potássio, os valores obtidos nas plantas do sistema hidropônico também foram significativamente superiores às do sistema convencional e não apresentaram um comportamento definido durante o desenvolvimento da cultura, ao contrário do sistema convencional, em que houve um aumento progressivo com o tempo (Tabela 3). 
Beninni, E. R. Y.; Takahashi, H. W.; Neves, C. S. V. J.

Tabela 3 - Concentração média de nutrientes $\left(\mathrm{g} \mathrm{Kg}^{-1}\right)$ na parte aérea de alface cv. Verônica, durante o desenvolvimento da cultura, cultivada em sistemas hidropônico e convencional. Londrina, UEL, 2001.

\begin{tabular}{|c|c|c|c|c|c|c|c|c|}
\hline \multirow[t]{2}{*}{ Dias } & \multicolumn{2}{|c|}{ Hidropônico } & \multicolumn{2}{|c|}{ Convenc. } & Hidropônico & Convenc. & \multicolumn{2}{|l|}{ Hidropônico } \\
\hline & \multicolumn{4}{|c|}{ Nitrogênio } & \multicolumn{2}{|c|}{ Fósforo } & \multicolumn{2}{|r|}{ Potássio } \\
\hline 0 & 37,58 & $\mathrm{a} \mathrm{C}^{(1)}$ & 37,58 & $\mathrm{aC}$ & 7,53 a $\mathrm{AB}$ & 7,53 a A & 20,00 a C & 20,00 a D \\
\hline 7 & 41,08 & a BC & 27,11 & b D & 5,72 a C & 4,60 b B & 89,74 a $\mathrm{A}$ & $40,00 \quad \mathrm{~b} \mathrm{C}$ \\
\hline 14 & 45,74 & a A & 45,69 & $\mathrm{a} A B$ & 6,64 a BC & 5,39 b B & 85,08 a $\mathrm{AB}$ & 41,67 b C \\
\hline 21 & 44,73 & a A & 45,99 & a A & 7,62 a $\mathrm{AB}$ & 4,62 b B & 72,26 a B & $52,50 \mathrm{~b} \mathrm{BC}$ \\
\hline 28 & 45,59 & $\mathrm{~b} A$ & 48,91 & a A & 8,73 a $\mathrm{A}$ & 5,08 b B & 87,42 a $\mathrm{AB}$ & $65,00 \mathrm{~b} \mathrm{AB}$ \\
\hline 35 & 44,58 & $\mathrm{~b}$ AB & 47,09 & a A & 8,80 a $A$ & 4,83 b B & 90,91 a A & 64,17 b AB \\
\hline 42 & 44,80 & a A & 42,27 & $\mathrm{~b} B$ & 8,54 a A & 5,59 b B & 87,42 a $\mathrm{AB}$ & 64,17 b AB \\
\hline \multirow[t]{3}{*}{49} & - & & 38,24 & $\mathrm{C}$ & - & $5,74 \quad$ B & - & 78,33 \\
\hline & $\mathrm{CV}_{1}^{(2)}=$ & $=3,98 \%$ & $\mathrm{CV}_{2}=4$, & $74 \%$ & $\mathrm{CV}_{1}=15,46^{\circ}$ & $\mathrm{CV}_{2}=11,44 \%$ & $\mathrm{CV}_{1}=12,64 \%$ & $\mathrm{CV}_{2}=13,17 \%$ \\
\hline & \multicolumn{4}{|c|}{ Cálcio } & \multicolumn{2}{|c|}{ Magnésio } & \multicolumn{2}{|r|}{ Enxofre } \\
\hline 0 & 13,08 & a A & 13,08 & a BC & 6,80 a $A$ & 6,80 a $A$ & 4,11 a $A$ & 4,11 a $\mathrm{ABC}$ \\
\hline 7 & 12,14 & $\mathrm{~b} A$ & 15,88 & $\mathrm{a} A B$ & 4,04 b B & 5,51 a B & 2,78 b B & 3,68 a CD \\
\hline 14 & 12,72 & $\mathrm{~b} A$ & 15,01 & a $\mathrm{ABC}$ & 4,04 a B & 4,34 a C & 2,48 b BC & 3,86 a $\mathrm{BCD}$ \\
\hline 21 & 12,13 & $\mathrm{~b} A$ & 14,46 & a $\mathrm{ABC}$ & 4,26 a B & 3,96 a $\mathrm{CDE}$ & 2,44 b BC & 3,05 a $E$ \\
\hline 28 & 11,13 & b A & 16,42 & a A & 3,74 b BC & 4,27 a CD & 2,47 b BC & 3,50 a DE \\
\hline 35 & 10,20 & b A & 15,03 & a $\mathrm{ABC}$ & 3,36 a C & 3,69 a DEF & $2,30 \mathrm{~b} \mathrm{C}$ & 4,31 a $\mathrm{AB}$ \\
\hline 42 & 10,29 & b A & 14,46 & a $\mathrm{ABC}$ & 3,31 a C & 3,49 a $E F$ & 2,32 b BC & 4,49 a $\mathrm{A}$ \\
\hline 49 & - & & 12,23 & $\mathrm{C}$ & - & 3,11 & - & $3,87 \quad \mathrm{BCD}$ \\
\hline & \multicolumn{4}{|c|}{$\mathrm{CV}_{1}=15,58 \%$} & \multicolumn{2}{|c|}{$\mathrm{CV}_{1}=10,61 \% \quad \mathrm{CV}_{2}=8,36 \%$} & & $\mathrm{CV}_{1}=3,40 \% \mathrm{CV}_{2}=8,00 \%$ \\
\hline
\end{tabular}

${ }^{(1)}$ Médias seguidas de mesma letra minúscula na linha e maiúscula na coluna não diferem entre si, pelo teste de Tukey a $5 \% \cdot{ }^{(2)} \mathrm{CV}_{1}=$ Coeficiente de variação da parcela; $\mathrm{CV}_{2}=$ Coeficiente de variação da subparcela.

As concentrações de cálcio nas plantas cultivadas em sistema hidropônico não apresentaram diferenças estatísticas ao longo do ciclo da cultura, diferentemente dos dados obtidos no cultivo à campo. Nas plantas do sistema convencional, essas concentrações foram superiores às do sistema hidropônico em todas as coletas. As concentrações de magnésio apresentaram queda durante o desenvolvimento da planta nos dois sistemas de cultivo. Aos 7 e 28 dias após transplante, as concentrações de magnésio das plantas do sistema hidropônico foram inferiores às do sistema convencional. As concentrações de enxofre das plantas cultivadas no sistema hidropônico foram constantes após 14 dias de transplante e no sistema convencional apresentaram oscilações durante todo o ciclo da cultura, além de serem superiores às concentrações obtidas nas plantas cultivadas em sistema hidropônico (Tabela 3). Em sistema de cultivo hidropônico, Koefender (1996) obteve na colheita valores entre 36,36 e 43,46;7,33 e 9,52; 61,97 e 71,14; 9,34 e 10,7, 2,11 e 2,67; 2,26 e 2,27 $\mathrm{g} \mathrm{Kg}^{-1}$ para N, P, $\mathrm{K}, \mathrm{Ca}, \mathrm{Mg}$ e $\mathrm{S}$, valores próximos aos obtidos neste experimento. Em sistema convencional esses valores foram entre 37,0 e 32,$7 ; 7,8$ e 8,0; 60,4 e 80,4; 12,6 e 15,$8 ; 3,7$ e 4,1; 1,6 $\mathrm{g} \mathrm{Kg}^{-1}$, respectivamente (GARCIA, 1982). Também em sistema convencional, Archila et al. (1997) verificaram valores entre 78 e 104; 6,2 e 6,4; 118 e 130; 6,0 e 6,8; 3,2 e 3,3 g Kg $^{-1}$ para $\mathrm{N}, \mathrm{P}, \mathrm{K}, \mathrm{Ca}$ e $\mathrm{Mg}$, respectivamente. Com exceção do P e S obtidos por Garcia (1982) e N, K e Ca por Archila et al. (1997), as concentrações dos demais nutrientes foram semelhantes aos deste experimento. 
Todos os nutrientes avaliados nas plantas cultivadas no sistema hidropônico apresentaram acúmulo lento até os 21 dias após transplante, tornando-se mais intenso após este período. Em torno de $47 \%$ do acúmulo total de $\mathrm{N}, \mathrm{P}, \mathrm{K}, \mathrm{Ca}, \mathrm{Mg}$ e $\mathrm{S}$ ocorreram nas duas últimas semanas de cultivo (Tabelas 4 e 5). Aos 42 dias após transplante, o acúmulo de $\mathrm{N}, \mathrm{P}, \mathrm{K}, \mathrm{Ca}$ e $\mathrm{Mg}$ da parte aérea das plantas cultivadas no sistema hidropônico foram superiores ao do sistema convencional; já o acúmulo de enxofre foi semelhante nos dois sistemas de cultivo (Tabela 4). Esses resultados possivelmente estão relacionados com a maior eficiência de absorção em soluções nutritivas, devido à não limitação de difusão dos elementos que ocorrem em diversos substratos (GRAVES, 1983). Koefender (1996) obteve valores de acúmulo de $\mathrm{N}, \mathrm{P}, \mathrm{K}, \mathrm{Ca}, \mathrm{Mg}$ e $\mathrm{S}$ em mg por planta entre 308 e 432,8; 63,8 e 95,1; 600,4 e 670,8; 84,0 e 97,$8 ; 19,8$ e 25,98; 19,4 e 23,7 respectivamente. Os valores por planta encontrado por Economakis e Koleilat (1997) variaram entre 230 e $605 \mathrm{mg}$ de N; 168 e $185 \mathrm{mg}$ de $\mathrm{P} ; 1.270$ e $1.283 \mathrm{mg}$ de K. As extrações totais de $\mathrm{N}, \mathrm{P}, \mathrm{K}, \mathrm{Ca}, \mathrm{Mg}$ e S em Kg ha ${ }^{-1}$ neste experimento foram: 89,$63 ; 17,99 ; 164,56 ; 18,77$; 6,05 e 5,43, respectivamente (Tabela 2).

A tendência do acúmulo de nutrientes pelas plantas cultivadas em sistema convencional foi semelhante às plantas cultivadas em sistema hidropônico, porém de maneira mais lenta (Tabelas 4 e 5), provavelmente devido à substituição das raízes existentes por novas por ocasião do transplante. O crescimento e o acúmulo de nutrientes nos estudos realizados por Garcia (1982) também foi lento até 30 dias após emergência. Fernandes, Oliveira e Haag (1981) verificaram que um terço do $\mathrm{Ca}, \mathrm{Mg}$ e $\mathrm{S}$ e $50 \%$ do $\mathrm{N}$ e $\mathrm{S}$ haviam sido absorvidos até os 40 dias após transplante. De acordo com Shenk e Barber (1979), o efeito da morfologia do sistema radicular sobre a absorção de nutrientes depende da superfície de absorção do sistema radicular, do volume de solo explorado e da concentração de nutrientes na solução do solo.

A extração de macronutrientes pela parte aérea, em Kg ha-1, no sistema convencional, encontra-se na Tabela 05. Garcia (1982) obteve valores médios de 42,0; 9,5; 84,35; 17,4; 4,93 e 2,0 $\mathrm{Kg} \mathrm{ha}^{-1}$ para N, P, $\mathrm{K}, \mathrm{Ca}, \mathrm{Mg}$ e $\mathrm{S}$, sendo que $\mathrm{N}$, K e $\mathrm{S}$ foram inferiores aos deste experimento. Fernandes, Oliveira e Haag (1981) obtiveram 23,2; 4,4; 50,9; 13,3; 3,2 e 3,0 Kg $\mathrm{ha}^{-1}$, respectivamente, todos inferiores aos deste experimento.

O acúmulo de nutrientes está diretamente relacionado ao acúmulo de matéria seca nas plantas de alface, tanto de cultivo hidropônico como convencional (Tabela 6). Resultados semelhantes foram obtidos por Garcia (1982) e Terra et al. (2001), em alface cultivada em sistema convencional.

Os nutrientes analisados nas plantas cultivadas em sistema hidropônico apresentaram a seguinte ordem $\mathrm{K}>\mathrm{N}>\mathrm{Ca}>\mathrm{P}>\mathrm{Mg}>\mathrm{S}$ e para as plantas cultivadas em sistema convencional foram $\mathrm{K}>\mathrm{N}>$ $\mathrm{Ca}>\mathrm{P}>\mathrm{S}>\mathrm{Mg}$. Com exceção do magnésio e do enxofre, dados semelhantes foram obtidos por Koefender (1996) em cultivos hidropônicos e por Fernandes, Oliveira e Haag (1981) e Garcia (1982) em cultivo a campo. 
Tabela 4 - Acúmulo de macronutrientes primário (mg por planta) em alface, cv. Verônica, cultivada em sistemas hidropônico e convencional, durante o desenvolvimento da cultura. UEL, Londrina, 2001.

\begin{tabular}{|c|c|c|c|c|c|c|c|c|c|}
\hline \multirow{3}{*}{$\begin{array}{l}\text { Dias } \\
\text { após } \\
\text { transp. }\end{array}$} & \multirow{2}{*}{\multicolumn{3}{|c|}{$\frac{\text { CONVENCIONAL }}{\text { Total }}$}} & \multicolumn{6}{|c|}{ HIDROPÔNICO } \\
\hline & & & & \multicolumn{2}{|c|}{ P. aérea } & \multicolumn{2}{|c|}{ Raiz } & \multicolumn{2}{|c|}{ Total } \\
\hline & $\mathrm{mg}$ & & $\%$ & $\mathrm{mg}$ & $\%$ & $\mathrm{mg}$ & $\%$ & $\mathrm{mg}$ & $\%$ \\
\hline & \multicolumn{9}{|c|}{ Nitrogênio } \\
\hline 0 & 4,82 & $a^{a}$ & 1,29 & 4,82 a & & 0,60 & 0,65 & 5,41 & 0,81 \\
\hline 7 & 5,78 & $\mathrm{a}$ & 1,55 & 24,21 a & 4,17 & 5,50 & 6,04 & 29,72 & 4,42 \\
\hline 14 & 18,26 & $\mathrm{~b}$ & 4,90 & 69,00 a & 11,87 & 16,65 & 18,27 & 85,65 & 12,74 \\
\hline 21 & 39,18 & $\mathrm{~b}$ & 10,51 & $115,02 \mathrm{a}$ & 19,79 & 29,48 & 32,34 & 144,49 & 21,49 \\
\hline 28 & 92,16 & $\mathrm{~b}$ & 24,72 & 292,66 a & 50,36 & 58,90 & 64,62 & 349,55 & 52,00 \\
\hline 35 & 191,54 & $\mathrm{~b}$ & 51,38 & 424,12 a & 72,99 & 68,10 & 74,72 & 492,22 & 73,22 \\
\hline 42 & 288,00 & $\mathrm{~b}$ & 77,26 & 581,10 a & 100,00 & 91,14 & 100,00 & 672,24 & 100,00 \\
\hline \multirow[t]{3}{*}{49} & 372,78 & & 100,00 & - & - & - & - & - & - \\
\hline & \multicolumn{7}{|c|}{$\mathrm{CV}_{1}{ }^{(2)}=25,35 \% \quad \mathrm{CV}_{2}=18,44 \%$} & & \\
\hline & \multicolumn{9}{|c|}{ Fósforo } \\
\hline 0 & 0,96 & $\mathrm{a}$ & 1,71 & 0,96 a & 0,87 & 0,17 & 0,70 & 1,14 & 0,85 \\
\hline 7 & 0,97 & $\mathrm{a}$ & 1,73 & 3,34 a & 3,02 & 1,26 & 5,17 & 4,61 & 3,44 \\
\hline 14 & 2,15 & $\mathrm{a}$ & 3,83 & 10,03 a & 9,07 & 3,28 & 13,42 & 13,30 & 9,93 \\
\hline 21 & 3,96 & $\mathrm{~b}$ & 7,06 & $19,67 \mathrm{a}$ & 17,78 & 6,25 & 25,62 & 25,93 & 19,35 \\
\hline 28 & 9,88 & $\mathrm{~b}$ & 17,61 & 55,85 a & 50,50 & 13,06 & 53,51 & 68,91 & 51,42 \\
\hline 35 & 19,66 & $\mathrm{~b}$ & 35,04 & 83,72 a & 75,70 & 16,10 & 65,96 & 99,82 & 74,49 \\
\hline 42 & 38,20 & $\mathrm{~b}$ & 68,08 & 110,60 a & 100,00 & 24,40 & 100 & 134,01 & 100,00 \\
\hline \multirow[t]{3}{*}{49} & 56,11 & & 100,00 & & - & - & - & - & - \\
\hline & \multicolumn{7}{|c|}{$\mathrm{CV}_{1}=24,72 \% \quad \mathrm{CV}_{2}=22,81 \%$} & & \\
\hline & \multicolumn{9}{|c|}{ Potássio } \\
\hline 0 & 2,56 & $\mathrm{a}$ & 0,33 & 2,56 a & 0,23 & 0,61 & 0,62 & 3,17 & 0,75 \\
\hline 7 & 8,48 & $\mathrm{a}$ & 1,11 & 53,03 a & 4,67 & 4,64 & 4,71 & 57,67 & 4,67 \\
\hline 14 & 16,66 & $\mathrm{~b}$ & 2,18 & 127,80 a & 11,25 & 15,18 & 15,42 & 142,98 & 11,58 \\
\hline 21 & 45,34 & $\mathrm{~b}$ & 5,92 & 187,33 a & 16,49 & 30,71 & 31,19 & 218,04 & 17,67 \\
\hline 28 & 120,20 & $\mathrm{~b}$ & 15,70 & 561,20 a & 49,41 & 66,22 & 67,25 & 627,43 & 50,84 \\
\hline 35 & 261,61 & $\mathrm{~b}$ & 34,16 & 863,92 a & 76,06 & 82,19 & 83,47 & 946,11 & 76,66 \\
\hline 42 & 434,93 & $\mathrm{~b}$ & 56,79 & 1135,76 a & 100,00 & 98,47 & 100,00 & 1234,23 & 100,00 \\
\hline \multirow[t]{2}{*}{49} & 765,84 & & 100,00 & - & - & - & - & - & - \\
\hline & \multicolumn{7}{|c|}{$\mathrm{CV}_{1}=28,31 \% \mathrm{CV}_{2}=17,96 \%$} & & \\
\hline
\end{tabular}

(1) Médias seguidas de mesma letra na linha, não diferem entre si, pelo Teste de Tukey a 5\%.

${ }^{(2)} \mathrm{CV}_{1}=$ Coeficiente de variação da parcela; $\mathrm{CV}_{2}=$ Coeficiente de variação da subparcela. 
Tabela 5 - Acúmulo de macronutrientes secundário (mg por planta) em alface, cv. Verônica, cultivada em sistemas hidropônico e convencional, durante o desenvolvimento da cultura. UEL, Londrina, 2001.

\begin{tabular}{|c|c|c|c|c|c|c|c|c|c|c|}
\hline \multirow{3}{*}{$\begin{array}{l}\text { Dias } \\
\text { após } \\
\text { transp. }\end{array}$} & \multirow{2}{*}{\multicolumn{3}{|c|}{$\begin{array}{c}\text { CONVENCIONAL } \\
\text { Total }\end{array}$}} & \multicolumn{7}{|c|}{ HIDROPÔNICO } \\
\hline & & & & \multicolumn{3}{|c|}{ P. aérea } & \multicolumn{2}{|c|}{ Raiz } & \multicolumn{2}{|c|}{ Total } \\
\hline & $\mathrm{mg}$ & & $\%$ & $\mathrm{mg}$ & & $\%$ & $\mathrm{mg}$ & $\%$ & $\mathrm{mg}$ & $\%$ \\
\hline & \multicolumn{10}{|c|}{ Cálcio } \\
\hline 0 & 1,68 & $a^{(1)}$ & 1,41 & 1,68 & $\mathrm{a}$ & 1,26 & 0,11 & 1,52 & 1,78 & 1,27 \\
\hline 7 & 3,43 & $\mathrm{a}$ & 2,88 & 7,20 & $\mathrm{a}$ & 5,38 & 0,27 & 3,92 & 7,47 & 5,31 \\
\hline 14 & 6,01 & $\mathrm{a}$ & 5,05 & 19,01 & $\mathrm{a}$ & 14,21 & 0,92 & 13,22 & 19,93 & 14,16 \\
\hline 21 & 12,23 & $\mathrm{a}$ & 10,27 & 26,01 & $\mathrm{a}$ & 19,44 & 1,54 & 21,99 & 27,54 & 19,56 \\
\hline 28 & 30,80 & $\mathrm{~b}$ & 25,87 & 71,29 & $\mathrm{a}$ & 53,28 & 3,59 & 51,37 & 74,88 & 53,18 \\
\hline 35 & 61,04 & $\mathrm{~b}$ & 51,27 & 98,03 & $\mathrm{a}$ & 73,26 & 6,38 & 91,26 & 104,41 & 74,15 \\
\hline 42 & 98,28 & $\mathrm{~b}$ & 82,5 & 133,81 & $\mathrm{a}$ & 100,00 & 6,99 & 100,00 & 140,80 & 100,00 \\
\hline \multirow[t]{3}{*}{49} & 119,05 & & 100,00 & - & & - & - & - & - & - \\
\hline & \multicolumn{10}{|c|}{$\mathrm{CV} 1^{(2)}=41,23 \% \mathrm{CV}_{2}=25,35 \%$} \\
\hline & \multicolumn{10}{|c|}{ Magnésio } \\
\hline 0 & 0,87 & $\mathrm{a}$ & 2,86 & 0,87 & & 2,02 & 0,07 & 3,03 & 0,95 & 2,08 \\
\hline 7 & 1,19 & $\mathrm{a}$ & 3,91 & 2,39 & $\mathrm{a}$ & 5,56 & 0,18 & 7,42 & 2,57 & 5,66 \\
\hline 14 & 1,73 & $\mathrm{~b}$ & 5,68 & 6,05 & $\mathrm{a}$ & 14,08 & 0,50 & 20,45 & 6,55 & 14,42 \\
\hline 21 & 3,35 & $\mathrm{~b}$ & 11,00 & 10,95 & $\mathrm{a}$ & 25,48 & 0,82 & 33,61 & 11,77 & 25,91 \\
\hline 28 & 7,99 & $\mathrm{~b}$ & 26,23 & 23,98 & $\mathrm{a}$ & 55,81 & 1,48 & 60,49 & 25,45 & 56,06 \\
\hline 35 & 14,99 & $\mathrm{~b}$ & 49,21 & 32,09 & $\mathrm{a}$ & 74,68 & 2,39 & 97,95 & 34,48 & 75,94 \\
\hline 42 & 23,70 & $\mathrm{~b}$ & 77,81 & 42,97 & $\mathrm{a}$ & 100,00 & 2,44 & 100,00 & 45,41 & 100,00 \\
\hline \multirow[t]{3}{*}{49} & 30,46 & & 100,00 & - & & - & - & - & - & - \\
\hline & & $\mathrm{CV}$ & $=34,52 \%$ & $V_{2}=20,9$ & $95 \%$ & & & & & \\
\hline & \multicolumn{10}{|c|}{ Enxofre } \\
\hline 0 & 0,53 & $\mathrm{a}$ & 1,40 & 0,53 & $\mathrm{a}$ & 1,76 & 0,14 & 1,31 & 0,67 & 1,64 \\
\hline 7 & 0,78 & $\mathrm{a}$ & 2,06 & 1,64 & $\mathrm{a}$ & 5,45 & 0,55 & 5,18 & 2,19 & 5,38 \\
\hline 14 & 1,54 & $\mathrm{a}$ & 4,07 & 3,73 & $\mathrm{a}$ & 12,40 & 1,49 & 14,02 & 5,22 & 12,82 \\
\hline 21 & 2,58 & $\mathrm{~b}$ & 6,82 & 6,29 & $\mathrm{a}$ & 20,91 & 2,53 & 23,78 & 8,82 & 21,66 \\
\hline 28 & 6,88 & $\mathrm{~b}$ & 18,20 & 15,88 & $\mathrm{a}$ & 52,79 & 5,80 & 54,46 & 21,69 & 53,24 \\
\hline 35 & 17,63 & $\mathrm{a}$ & 46,63 & 21,84 & $\mathrm{a}$ & 72,61 & 7,48 & 70,22 & 29,32 & 71,99 \\
\hline 42 & 30,66 & $\mathrm{a}$ & 81,09 & 30,08 & $\mathrm{a}$ & 100,00 & 10,65 & 100,00 & 40,73 & 100,00 \\
\hline \multirow[t]{2}{*}{49} & 37,81 & & 100,00 & - & & - & - & - & - & - \\
\hline & \multicolumn{10}{|c|}{$\mathrm{CV}_{1}=28,30 \% \mathrm{CV}_{2}=19,30 \%$} \\
\hline
\end{tabular}

(1) Médias seguidas de mesma letra na linha, não diferem entre si, pelo Teste de Tukey a $5 \%$.

${ }^{(2)} \mathrm{CV}_{1}=$ Coeficiente de variação da parcela; $\mathrm{CV}_{2}=$ Coeficiente de variação da subparcela.

Tabela 6 - Coefíciente de correlação $(\mathrm{p}<0,01)$ entre acúmulo de matéria seca $(\mathrm{g})$ e nutrientes $(\mathrm{mg})$ em alface, cv. Verônica, cultivada em sistemas hidropônico e convencional. UEL, Londrina, 2001.

\begin{tabular}{lcccccc}
\hline \multicolumn{1}{c}{ Peso seco } & $\mathrm{N}$ & $\mathrm{P}$ & $\mathrm{K}$ & $\mathrm{Ca}$ & $\mathrm{Mg}$ & $\mathrm{S}$ \\
\hline \multirow{2}{*}{$\begin{array}{c}\text { Parte aérea } \\
\text { Raiz }\end{array}$} & 0,9961 & 0,9893 & 0,9975 & 0,9740 & 0,9869 & 0,9984 \\
\hline \multirow{2}{*}{ Parte aérea } & 0,9991 & 0,9882 & 0,9816 & 0,9428 & 0,9439 & 0,9905 \\
\hline
\end{tabular}




\section{Conclusões}

1. O ciclo da alface convencional foi 7 dias maior do que hidropônico;

2. No sistema convencional o acúmulo de matéria seca da parte aérea foi lenta no ínicio do ciclo e rápida na última semana;

3. Todos os nutrientes avaliados nas plantas cultivadas no sistema hidropônico apresentaram acúmulo lento até os 21 dias após transplante, tornando-se mais intenso após este período;

4. O acúmulo de todos os macronutrientes em $\mathrm{mg} /$ planta no sistema hidropônico foram superiores ao convencional.

\section{Agradecimentos}

Os autores agradecem ao Professor Dr. Antônio Roque Dechen pelas sugestões e aos estagiários Roberto Lee, Regiane Cristine Filgueiras e Emerson Kazuo Takahashi pelo apoio nas análises laboratoriais.

\section{Referências}

ARCHILA P. J. A.; CONTRERAS N, U. H.; PINZÓN, H.; LAVERDE P, H. Absorcion de nutrientes en cuatro materiales de lechuga, Lactuca sativa L. Agronomia Colombiana, Bogotá, v. 14, p. 28-36, 1997.

COSTA, P. C.; DIDONE, E. B.; SESSO, T. M.; CAÑIZARES, K. A. L.; GOTO, R. Condutividade elétrica da solução nutritiva e produção de alface em hidroponia. Scientia Agrícola, Piracicaba, v. 58, n. 3, p. 595-597, 2001.

ECONOMAKIS, C. D.; KOLEILAT, R. Effect on nitrogen concentration on growth, water, and nutrient uptake of lettuce plants in solution culture. Acta Horticulturae, The Hague, n. 449, v. 2, p. 223-228, 1997.

FAQUIN, V.; FURLANI, P. R. Cultivo de hortaliças de folhas em hidroponia em ambiente protegido. Informe Agropecuário, Belo Horizonte, v. 20, n.200/2001, p. 99104, 1999.

FAQUIN, V.; FURTININETO,A.E.; VILELA,L.A.A.Produção de alface em hidroponia. Lavras: UFLA, 1996.50 p.

FERNANDES, P. D.; OLIVEIRA, G. D.; HAAG, H. P. Nutrição mineral de hortaliças. Absorção de macronutrientes pela cultura da alface. In: HAAG, H. P.; MINAMI, K. Nutrição mineral em hortaliças. Campinas: Fundação Cargill, 1981. p. 143-149.
FURLANI, P. R. Hydroponic vegetable production in Brazil. Acta Horticulturae, The Hague, v. 2, n. 481, p. 777778, 1999.

FURLANI, P. R.; SILVEIRA, L. C. P.; BOLONHEZI, D.; FAQUIN, V. Cultivo hidropônico de plantas. Campinas: Instituto Agronômico, 1999. 52 p. (Boletim técnico, 180).

GARCIA, L. L. C. Absorção de macro e micronutrientes e sintomas de carência de macronutrientes em alface (Lactuca sativa L.), cv. Brasil 48 e Clause's Aurélia. 1982. 78 p. Tese (Mestrado)-Escola Superior de Agricultura Luiz de Queiroz, Universidade de São Paulo, Piracicaba, 1982.

GRAVES, C. J. The nutrient film technique. Horticultural Reviews. New York, v. 5, p. 1-44, 1983.

GUALBERTO, R.; RESENDE, F. V.; BRAZ, L. T. Competição de cultivares de alface sob cultivo hidropônico "NFT" em três diferentes espaçamentos. Horticultura Brasileira, Brasília, v. 17, n. 2, p. 155-158, 1999.

HEINEN, M.; JAGER, A.; NIERS, H. Uptake of nutrients by lettuce on NFT with controlled composition of the nutrient solution. Netherlands Journal of Agricultural Science, Wageningen, v. 39, p. 197-212, 1991.

HOAGLAND, D. R.; ARNON, D. I. The water culture method for growing plants without soil. England: California Agricultural Experiment Station, 1950.31 p.

KOEFENDER, V. N. Crescimento e absorção de nutrientes pela alface cultivada em fluxo laminar de solução. 1996. 85 p. Tese (Mestrado)- Escola Superior de Agricultura Luiz de Queiroz, Universidade de São Paulo, Piracicaba, 1996.

MEDINA, P. V. L.; SILVA, V. F.; CARDOSO, A. A.; CAMPOS, J. P. Perda na qualidade da alface (Lactuca sativa L.) durante o armazenamento. I. Relação entre as mudanças metabólicas. Revista Ceres, Viçosa, v. 163, n. 29 p. 259-267, 1982.

PAPADOPOULOS, A. P.; KHOSLA, S. Concepts and methodology for fertilizer use economy in greenhouse tomato production, in Canadá. Acta Horticulturae, The Hague, v. 1, n. 401, p. 461-471, 1995.

RODRIGUES, E. T.; CASALI, V. W. D. Rendimento e concentração de nutrientes em alface, em função das adubações orgânica e mineral. Horticultura Brasileira, Brasília, v. 17, n. 2, p. 125-128, 1999.

SHENK, M. K.; BARBER, S. A. Root characteristics of corn genotypes as related to P uptake. Agronomy Journal, Madison, v. 71, n. 6, p. 921-924, 1979.

SUTCLIFFE, J. F.; BAKER, D. A. Las plantas y las sales minerales. Barcelona: Omega, 1983. 74 p.

TERRA, S. B.; MARTINS, S. R.; FERNANDES, H. S.; DUARTE, G. B. Exportação de macronutrientes em alface cultivada no outono-inverno e na primavera com adubação orgânica em ambiente protegido. Horticultura Brasileira, Brasília, v. 19, n. 2, 2001. Suplemento CD-ROM. 